\title{
Movie Business Trend Prediction using Market Basket Analysis
}

\author{
Debaditya Barman \\ Assistant Professor, Department of Computer \\ Science \\ University of Gour Banga \\ Malda -732103, West Bengal, India
}

\author{
Nirmalya Chowdhury,Ph.D \\ Associate Professor, Department of Computer \\ Science and Engineering \\ Jadavpur University \\ Kolkata - 700032, India
}

\begin{abstract}
Trend analysis can be defined as a process of comparing past business data to identify any significant, consistent results or trends. It is very useful method to understand any business's performance. Successful business trend analysis can take business to the right direction. Film industry is the most important component of Entertainment industry. Profit and loss both are very high for this business. A large amount of money invested in this high risk industry. Before release of a particular movie, if the Production House gets any type of business trend prediction about how the film will do business, it can be helpful to reduce the risk. It is a known fact that viewer's taste in movies can change time to time. For instance in 2009, most profitable movie in USA was New Moon (1319.422\%) which belongs to Adventure, Drama and Fantasy genres. So, profitable trend determination by movie genre analysis can be helpful for making business decisions like marketing strategy, advertising strategy etc. In this work we have tried to determine and predict the trend in movie business by analyzing movie genres. Film genres find both academic and practical applications as films can be categorized by genre at every stage of their existence, from the initial approach the screenwriter takes, to where they end up on the shelves of our local store, to how their impact on cultural history is assessed. There is also a lot of commercial interest in the way people classify and choose to watch movies - this is very important for the initial marketing of a movie, and for companies like Netflix or LoveFilm, who rely on genre categories to help their customers make their picks.
\end{abstract}

\section{General Terms}

Machine intelligence, Pattern Recognition

\section{Keywords}

Film industry, Film genre, Trend prediction, Market Basket Analysis, Apriori rules

\section{INTRODUCTION}

A movie [1], also called a film or motion picture, is a series of still or moving images. It is produced by recording photographic images with cameras, or by creating images using animation techniques or visual effects.

Films are cultural artifacts created by specific cultures, which reflect those cultures, and, in turn, affect them. It is considered to be an important art form, a source of popular entertainment and a powerful method for educating or indoctrinating citizens. The visual elements of cinema give motion pictures a universal power of communication.
The process of filmmaking has developed into an art form and has created an industry in itself. Film Industry is an important part of present-day mass media industry or entertainment industry (also informally known as show business or show biz). This industry [2] consists of the technological and commercial institutions of filmmaking: i.e. film production companies, film studios, cinematography, film production, screenwriting, pre-production, post production, film festivals, distribution; and actors, film directors and other film crew personnel.

The major business centers of film making are in the United States, India, Hong Kong and Nigeria. The average cost [3] of a world wide release of a Hollywood film or American film (including pre-production, film and post-production, but excluding distribution costs) is about $\$ 65$ million. It can be stretched up to $\$ 300$ million [4] (Pirates of the Caribbean: At World's End). Worldwide gross revenue [5] can be almost $\$ 2.8$ billion (Avatar). Profit-loss is found to vary from a profit [6] of $2975.63 \%$ (City Island) to a loss [7] of $1299.7 \%$ (Zyzzyx Road).

It is a known fact that viewer's taste in movies can change time to time. Following examples can be helpful to illustrate this fact. In 2009 most profitable movie in USA was New Moon (1319.422\%) which belongs to Adventure, Drama and Fantasy genres. Paranormal Activity 2 released in 2010 was most profitable movie in USA $(5791.452 \%)$ a Horror movie. In 2011 most profitable movie in USA was Insidious (5606.421\%) which belongs to Horror and Thriller genres. So it is pretty clear that profitable trend determination and prediction can be helpful for making business decisions like marketing strategy, advertising strategy etc. Target audience also can be determined by using the MPAA (Motion Pictures Association of America) rating.

Association rule mining [8] finds interesting associations and/or correlation among large set of data items. Association rules show attributes value conditions that occur frequently together in a given dataset. Association rules also provide information of this type in the form of "if-then" statements. These rules are computed from the data and unlike the if-then rules of logic; association rules are probabilistic in nature. In addition to the antecedent (the "if" part) and the consequent (the "then" part), an association rule has generally two measurements (Support and Confidence) that express the interestingness about the rule.

Association rule mining has been successfully applied in Retail marketing [9], Medical Diagnosis [10], Analysis of Protein Sequences [11], Analysis of telephone calling patterns [12], Fraud detection [13], Analysis of Census Data [14] etc. 
The formulation of the problem is presented in the next section. Section III describes our proposed method. The proposed method is presented in the form of an algorithm in section III-A. Experimental results can be found in section IV. Concluding remarks and scope for further work have been incorporated in section $\mathrm{V}$.

\section{STATEMENT OF THE PROBLEM}

Every Film can be identified by certain film genres. In film theory, genre [15] refers to the method based on similarities in the narrative elements from which films are constructed. Most theories of film genre are borrowed from literary genre criticism. Some basic film genres are - action, adventure, animation, biography, comedy, crime, drama, family, fantasy, horror, mystery, romance, science-fiction, thriller, war etc. it One film can belong to more than one genre. As an example the movie titled "Alice in Wonderland (2010)" belongs to [16] action, adventure, and fantasy genres. Viewer's selection of a movie is often based on the film's genres. More viewers certainly can lead a movie to achieve more success. So we can say that any film's success is highly dependent on its film genres.

Inspired from "Market Basket Analysis"- a typical example of frequent item set mining, we have used it to predict movie trend. Viewer's choice of selection in movies has been analyzed by finding associations between different genres.

Each genre is represented by a Boolean variable which represents presence or absence of that genre in a particular movie. Thus each Movie or film can be represented by a Boolean vector of values assigned to these Boolean variables. These vectors can be analyzed for extracting the genres that are frequently associated or found together. For example in a certain month it may be found that those movies make profits which are having nonzero values for romantic and comedy genres. This type of association between genres and profit can be represented by following rule.

$$
\begin{gathered}
\text { Romantic }(\text { Yes }) \wedge \text { Comedy }(\text { Yes }) \Rightarrow \text { Profit }(\text { Yes }) \\
{[\text { support }=50 \%, \text { confidence }=95 \%]}
\end{gathered}
$$

Support and confidence are two measures of any rule's significant. They respectively reflect usefulness and certainty of discovered rules. A support of $50 \%$ means $50 \%$ of the entire movies under the analysis are romantic comedy and they made profit. A confidence of $95 \%$ means that $95 \%$ of all romantic comedy movies made profit. Typically, association rules can be considered as interesting if they satisfy both a minimum support and confidence threshold. We will discuss about these threshold values later.

These associations of genres can be treated as viewer's trend or movie business's trend. These business trends can help Film Distributors to develop business strategies that we have discussed earlier. For instance if in a certain month viewers are preferring romantic- comedy films, the distributors should launch their romantic-comedy films at that month. If previous month's trend was adventure-action film, then distributors should go for extensive advertising or marketing for their upcoming adventure-action films.

We have considered only successful movies (with a profit of more than $0 \%$ ) for our experiments. Due to lack of published materials, we cannot get any idea about the duration or lifetime of any such movie business trend. So for trend determination we have assumed that minimum lifetime of a movie business trend is one month. The lifetime of the trend is increased until we found another trend. We have generated a set of association rules (minimum support $=15 \%$, minimum confidence $=70 \%$ ) for each month from 2009 to 2011, using the genres of the movies released within a month. The genres associated with profit with highest support have been tagged as a profitable trend or trends. Note that we have achieved $100 \%$ confidence for 31 cases out of 36 cases and lowest confidence is found to be $80 \%$.

We have considered a five-month time frame as a maximum lifetime or duration of a movie trend. We have used first three month's data to compute three best trends and validated these trends by next two month's trend. At first the entire data set have been divided into 12partitions. Each partition consists with the data of 3 consecutive months. Three best association rules according to their support have been derived from the first 3 month's data, and then these rules are validated by the next two month's business trend. Note that As you can see, the results from our previous experiments (Business trend determination) have been used here to validate our forecasted result.

In data mining, association rule learning is a popular and wellexplored method for discovering interesting relations between variables in large databases [17]. It is intended to identify "strong rules" in databases using different measures of interestingness [18].By "strong rules" we mean the rules that satisfy both a minimum support and minimum confidence value. Based on the concept of strong rules, Rakesh Agrawal et al.[19] introduced association rules for discovering relations between products in large-scale transaction data recorded by point-of-sale (POS) systems in supermarkets. For example, the rule \{Onions, Potatoes $\Rightarrow$ \{Burger $\}$ found in the sales data of a supermarket would indicate that if a customer buys onions and potatoes together, he or she is likely to also buy hamburger meat. Such information can be used as the basis for decisions about marketing activities such as, e.g., promotional pricing or product placements [20]. In addition to the above example from market basket analysis, association rules are employed today in many application areas including Web usage mining [21, 22, 23 and 24], intrusion detection [25, 26, 27, 28, and 29], Continuous production [30] and bioinformatics [31, 32, 33, 34, and 35].

We have used Apriori algorithm [36] to determine association rules, which extract general trends in our movie database. It is a classic algorithm for frequent item set mining and association rule learning over transactional databases. In our case it proceeds by identifying the frequent individual profit making genres in the database and extending them to larger and larger genre sets as long as those genre sets appear sufficiently often in the database.

\section{PROPOSED METHOD}

As stated above we have used association rule mining approach to find profitable business trend in our movie database. Association rules are basically if/ then statement. We have used these rules to uncover relationships between movie genres. An association rule has two parts, an antecedent (if) and a consequent (then). An antecedent is an item found in the data [37]. A consequent is an item that is found in combination with the antecedent. In our case, combination of movie genres is an antecedent and the profit the movie makes is a consequent. As we have mentioned earlier we have measured the rule's interestingness according to its support and confidence.

We have applied apriori algorithm on each month's data to generate a set of rules. The rule having highest support and confidence value is issued to identify the profitable business trend for each month.

Let $\mathcal{J}=\left\{I_{1}, I_{2}, \ldots, I_{m}\right\}$ be a set of items that are actually movie attributes (movie genres and profit) [38]. Let $D$, the task relevant data, be a set of database transactions where each transaction $T$ is a set of items such that $T \subseteq \mathcal{J}$. Note that, in this case a movie is a transaction and $D$ is the movie database. Let $A$ be a set of items. A 
transaction $T$ is said to contain $A$ if and only if $A \subseteq T$. An association rule is an implication of the form $A \Rightarrow B$ where $A \subset \mathcal{J}, B \subset \mathcal{J}$, and $A \cap B=\phi$. In this case $A$ is the genres and $B$ is the profit. The rule $A \Rightarrow B$ holds in the movie database $D$ with support $s$, where $s$ is the percentage of movies that contain $A \cup B$. This is taken to be the probability $P(A \cup B)$. The rule $A \Rightarrow B$ has confidence $c$ in $D$, where $c$ is the percentage of movies in $D$ containing $A$ that also contain $B$. This is taken to be the conditional probability $P(B \mid A)$. That is,

$\operatorname{support}(A \Rightarrow B)=P(A \cup B)$

confidence $(A \Rightarrow B)=P(B \mid A)$

Rules that satisfy both a minimum support threshold (min_sup) and a minimum confidence threshold (min_conf) are called "strong rules".

A set of items be called an itemset. If an itemset contains $k$ items then it is a $k$-itemset. Like, the set $\{$ Romance, comedy, Profit\} is a three item set. The occurrence frequency of an itemset is the number of transactions that contain the particular itemset. This is also referred to as the frequency, support count, or count of the itemset. Note that the itemset's support defined in Equation (3.1) is sometimes referred to as relative support, whereas the occurrence frequency is called the absolute support. If the relative support of an itemset $I$ satisfies a prespecified minimum support threshold (i.e., the absolute support of I satisfies the corresponding minimum support count threshold), then $I$ is a frequent itemset. 3 The set of frequent $k$-itemsets is commonly denoted by $L_{k}$.

From equation (3.2), we have

$$
\begin{aligned}
& \text { confidence }(A \Rightarrow B)=P(B \mid A)=\frac{\text { support }(A \cup B)}{\text { support }(A)}= \\
& \frac{\text { support_count }(A \cup B)}{\text { support_count }(A)}
\end{aligned}
$$

Equation (3.3) shows that the confidence of the rule $A \Rightarrow B$ can be easily derived from the support counts of $A$ and $A \cup B$.

Algorithm 1: To generate the set of Association rules

\section{Input:}

- $\quad D$, the movie database;

- $\quad$ min_sup, the minimum support count threshold.

\section{Output:}

- $\quad L$, frequent itemsets in $D$.

\section{Method:}

1. $\quad L_{1}=$ find_frequent_1-itemsets $(D)$;

2. for $\left(k=2 ; L_{k-1} \neq \varnothing ; k++\right)\{$

3. $C_{k}=$ apriori_gen $\left(L_{k-1}\right)$;

4. for each movie $t \in D\{/ /$ scan $D$ for Counts

5. $C_{t}=$ subset $\left(C_{k}, t\right)$; // get the subsets of $t$ that are candidates

6. for each candidate $c \in C_{t}$

7. c. count ++ ;

$8 . \quad\}$

9. $L_{k}=\left\{c \in C_{k} \mid c\right.$. count $\left.\geq \min \sup \right\}$

10. $\}$

11. return $L=\cup_{k} L_{k}$;

Procedure apriori_gen $\left(L_{k-1}\right.$ : frequent $(k-1)$ - itemsets)

1. for each itemset $l_{1} \in L_{k-1}$

2. for each itemset $l_{2} \in L_{k-1}$

3. if $\left(l_{1}[1]=l_{2}[1]\right) \wedge\left(l_{1}[2]=l_{2}[2]\right) \wedge \ldots . \wedge\left(l_{1}[k-2]=\right.$ $l 2 k-2 \Lambda l 1 k-1<l 2 k-1$ then \{
Volume 74-No.9, July 2013

4. $\quad c=l_{1} \bowtie l_{2} ; / /$ join step: generate candidates

5. if has_infrequent_subset $\left(c, L_{k-1}\right)$ then

6. delete $c$;

7. else add c to $C_{k}$;

8. $\}$

9. return $C_{k}$;

Procedure has_infrequent_subset (c: candidate $k$-genreset);

$L_{k-1}$ : frequent $(k-1)-$ itemsets);//use prior knowledge

1. for each (k-1)- subset $s$ of $c$

2. if $s \notin L_{k-1}$ then

3. return TRUE;

4. return FALSE;

Apriori algorithm used level-wise iterative search approach. Here $k$ itemsets are used to explore $(k+1)$ itemsets. At first the set of frequent-1 itemsets, $L_{1}$ is found by scanning the movie database. Next $L_{1}$ is used to find $L_{2}$, the set of frequent 2 itemsets, which is used to find $L_{3}$, and so on, until no more frequent k-itemsets can be found[77]. If the itemsets $I$ does not satisfy the minimum support threshold, min_sup, then $I$ is not frequent; that is $P(I)<$ minifisup. If a genre $A$ is added to itemsets $I$, then the resulting itemsets (i.e. $I \cup A$ ) cannot occur more frequently than $I$. Therefore, $I \cup A$ cannot be frequent either. That is, $P(I \cup A)<\min$ sup.

A two step process Joining and Pruning are used in the apriori algorithm

\section{The Joining step:}

To find $L_{k}$, a set of candidate $k$-itemsets is created by joining $L_{k-1}$ with itself [39]. This set of candidates is $C_{k}$. Let $l_{1}, l_{2}$ be itemsets in $L_{k-1}$. The join $L_{k-1} \bowtie L_{k-1}$ is performed where members of $L_{k-1}$ are joinable if their first $(k-2)$ items are in common. That is, members $l_{1}$ and $l_{2}$ of $L_{k-1}$ are joined if $\left(l_{1}[1]=l_{2}[1]\right) \wedge\left(l_{1}[2]=l_{2}[2] \wedge . . \wedge\right.$ $\left.\left(l_{1}[k-2]=l_{2}[k-2]\right) \wedge\left(l_{1}[k-1]=l_{2}[k-1]\right)\right) . \quad$ The condition $l_{1}[k-1]<l_{2}[k-1]$ simply ensures that no duplicates are generated. The resulting itemset formed by joining $l_{1} l_{2}$ is $l_{1}[1], l_{1}[2], \ldots, l_{1}[k-2], l_{1}[k-1], l_{2}[k-1]$.

\section{The Pruning Step:}

$C_{k}$ is a superset of $L_{k}$, that means its members may not be frequent, but all of the frequent $k$-itemsets are included in $C_{k}$ [39]. A scan of the movie database to determine the count of each candidate in $C_{k}$ would result in the determination of $L_{k}$. To reduce the huge size of $C_{k}$ apriori used as follows. Any $(k-1)$ subset that is not frequent cannot be a subset of a frequent $k$-itemset. Hence, if any $(k-1)$ subset of a candidate $\mathrm{k}$-itemset is not in $L_{k-1}$, then the candidate cannot be frequent either and so can be removed from $C_{k}$.

Strong association rules (association rules that satisfy both minimum support and minimum confidence criteria) can be found from the frequent itemset generated from the movie database, D. Confidence can be found by the Equation (3.3).

Based on this equation, association rules can be generated as follows:

- $\quad$ For each frequent itemset $l$, generate all nonempty subsets of $l$.

- For every nonempty subset $s$ of $l$, output the rule "s $\Rightarrow(l-s) "$ if $\frac{\text { support_count }(l)}{\text { support_count }(s)} \geq \min$ inconf, where miniog conf is the minimum confidence threshold. 
Note that the rules are generated from frequent itemsets so each one automatically satisfies minimum support.

Algorithm 2: To predict profitable business trends for a particular month

Input:

- $D_{0}, D_{1}, D_{2}, D_{3}, \ldots, D_{10}$, Film's data base containing 3 month's data.

- $\quad$ min_sup, the minimum support count threshold.

Output:

- $\quad R$ the business trends forecast

Method:

1. $L_{i}=$ association rules;

2. for $(i=0 ; i<11 ; i++)\{$

3. $L_{i}=$ association_rule $\left(D_{i}\right.$, minis $\left.s u p\right)$;

4. $\quad R_{i}=$ best_3_rule $\left(L_{i}\right)$;

5. $\}$

6. $\operatorname{return} R=\mathrm{U}_{i} R_{i}$;

Procedure association_rule ( $D$, min sup)

1. for each dataset $D\{$

2. apriori $(D$, minisosup);

3. \}

Procedure best_3_rule $(L)$;

1. $l_{i} \in L$

2. descending_sort_support_and_confidence $(L)$;

3. Select first 3 rules $l_{1}, l_{2}, l_{3}$;

First of all we have extracted 3 best association rules from the first three month's data. These rules are then used to predict the business trend for the next two months. In this way we have predicted the trend for the eleven data partitions, which means twenty-two month's business trend. We have validated these results by the results of previous experiment (Algorithm 1).

\section{EXPERIMENTAL RESULT}

We have used 395 movie's data released from 2009 to 2011. The data attributes are USA Release date, 20 movie genres (like Action, Adventure, Animation, Biography, Comedy, Crime, Documentary, Drama, Family, Fantasy, History, Horror, Musical, Mystery, Romance, Science Fiction, Sport, Thriller, War, Western) and Profit percentage. Except US Release date and profit percentage, all attributes' values are either " $y$ " or " $n$ ". Movies with less than $0 \%$ profit value, which is denoted by "n", are removed from the database. USA release date helps us to group the movies, which are released in same month. After month-wise grouping, we have removed this attribute. After preprocessing the database it is looked like as shown in Table 1.

Table 1. Snapshot of the data used for trend determination

\begin{tabular}{|l|l|l|l|l|l|l|l|}
\hline Action & Adventure & Fantasy & $\cdot$ & $\cdot$ & $\cdot$ & Western & Profit \\
\hline $\mathrm{y}$ & $\mathrm{y}$ & $\mathrm{n}$ & $\cdot$ & $\cdot$ & $\cdot$ & $\mathrm{n}$ & $\mathrm{y}$ \\
\hline $\mathrm{y}$ & $\mathrm{n}$ & $\mathrm{n}$ & $\cdot$ & $\cdot$ & $\cdot$ & $\mathrm{n}$ & $\mathrm{y}$ \\
\hline $\mathrm{n}$ & $\mathrm{n}$ & $\mathrm{y}$ & $\cdot$ & $\cdot$ & $\cdot$ & $\mathrm{y}$ & $\mathrm{n}$ \\
\hline
\end{tabular}

\begin{tabular}{|l|l|l|l|l|l|l|l|}
\hline $\mathrm{n}$ & $\mathrm{y}$ & $\mathrm{y}$ & $\cdot$ & $\cdot$ & $\cdot$ & $\mathrm{n}$ & $\mathrm{y}$ \\
\hline
\end{tabular}

We have carried out our experiment using SPSS Clementine 11.1 Software. Minimum support and confidence are set to $15 \%$ and $70 \%$ respectively. Maximum number of antecedents is set to three, because we have not found any film that belongs to more than three genres.

As we have mentioned in Section II, at first we have generated a set of association rules (minimum support $=15 \%$, minimum confidence: $70 \%$ ) for each month from 2009 to 2011 , using the genres of the movies released within a month. The genres with highest support have been tagged as a profitable trend or trends. We have provided the results in Table 2.One can see from the table that, we have achieved $100 \%$ confidence level for 31 cases out of 36 cases and lowest confidence level is $80 \%$.

Table 2. Month wise trend for the successful movies

\begin{tabular}{|c|c|c|c|}
\hline \multirow[t]{2}{*}{ Month } & \multicolumn{3}{|l|}{ Trend } \\
\hline & Antecedent & Support & Confidence \\
\hline Jan 09 & Comedy $=Y$ & 57.14 & 100.00 \\
\hline Feb 09 & Action $=\mathrm{Y}$ & 40.00 & 100.00 \\
\hline Mar 09 & Action $=\mathrm{Y}$ & 57.14 & 100.00 \\
\hline Apr 09 & Drama $=Y$ & 80.00 & 100.00 \\
\hline May 09 & Action $=\mathrm{Y}$ & 66.67 & 100.00 \\
\hline Jun 09 & Drama $=Y$ & 41.67 & 80.00 \\
\hline Jul 09 & Adventure $=\mathrm{Y}$ & 40.00 & 100.00 \\
\hline Aug 09 & Thriller/Drama $=\mathrm{Y}$ & 27.27 & 100.00 \\
\hline Sep 09 & Comedy $=Y$ & 38.46 & 100.00 \\
\hline Oct 09 & Thriller $=\mathrm{Y}$ & 20.00 & 100.00 \\
\hline Nov 09 & Comedy $=Y$ & 35.29 & 100.00 \\
\hline Dec 09 & $\begin{array}{l}\text { Action/ Adventure/Fantasy = } \\
\text { Y }\end{array}$ & 21.43 & 100.00 \\
\hline Jan 10 & Action $=\mathrm{Y}$ & 60.00 & 100.00 \\
\hline Feb 10 & Action $=\mathrm{Y}$ & 37.50 & 100.00 \\
\hline Mar 10 & Comedy $=\mathrm{Y}$ & 58.33 & 100.00 \\
\hline Apr 10 & Comedy $=Y$ & 62.50 & 100.00 \\
\hline May 10 & Action $=Y$ & 66.67 & 100.00 \\
\hline Jun 10 & Comedy $=\mathrm{Y}$ & 45.45 & 100.00 \\
\hline Jul 10 & Action/ Adventure $=\mathrm{Y}$ & 40.00 & 100.00 \\
\hline
\end{tabular}




\begin{tabular}{|l|l|l|l|}
\hline Aug 10 & Crime $=$ Y & 30.00 & 100.00 \\
\hline Sep 10 & Comedy $=$ Y & 38.46 & 100.00 \\
\hline Oct 10 & Action $=$ Y & 16.67 & 100.00 \\
\hline Nov 10 & Drama $=$ Y & 81.81 & 100.00 \\
\hline Dec 10 & Drama $=$ Y & 58.33 & 85.71 \\
\hline Jan 11 & Comedy $=$ Y & 42.86 & 100.00 \\
\hline Feb 11 & Drama $=$ Y & 36.36 & 100.00 \\
\hline Mar 11 & Science Fiction $=$ Y & 33.33 & 100.00 \\
\hline Apr 11 & Thriller $=$ Y & 21.05 & 100.00 \\
\hline
\end{tabular}

\begin{tabular}{|l|l|l|l|}
\hline May 11 & Comedy $=$ Y & 41.67 & 80.00 \\
\hline Jun 11 & Comedy $=$ Y & 54.55 & 83.33 \\
\hline Jul 11 & Comedy = Y & 53.85 & 100.00 \\
\hline Aug 11 & Drama = Y & 42.86 & 100.00 \\
\hline Sep 11 & Comedy = Y & 16.67 & 100.00 \\
\hline Oct 11 & Action = Y & 21.43 & 100.00 \\
\hline Nov 11 & Comedy $=$ Y & 70.00 & 100.00 \\
\hline Dec 11 & Comedy = Y & 54.55 & 83.330 \\
\hline
\end{tabular}

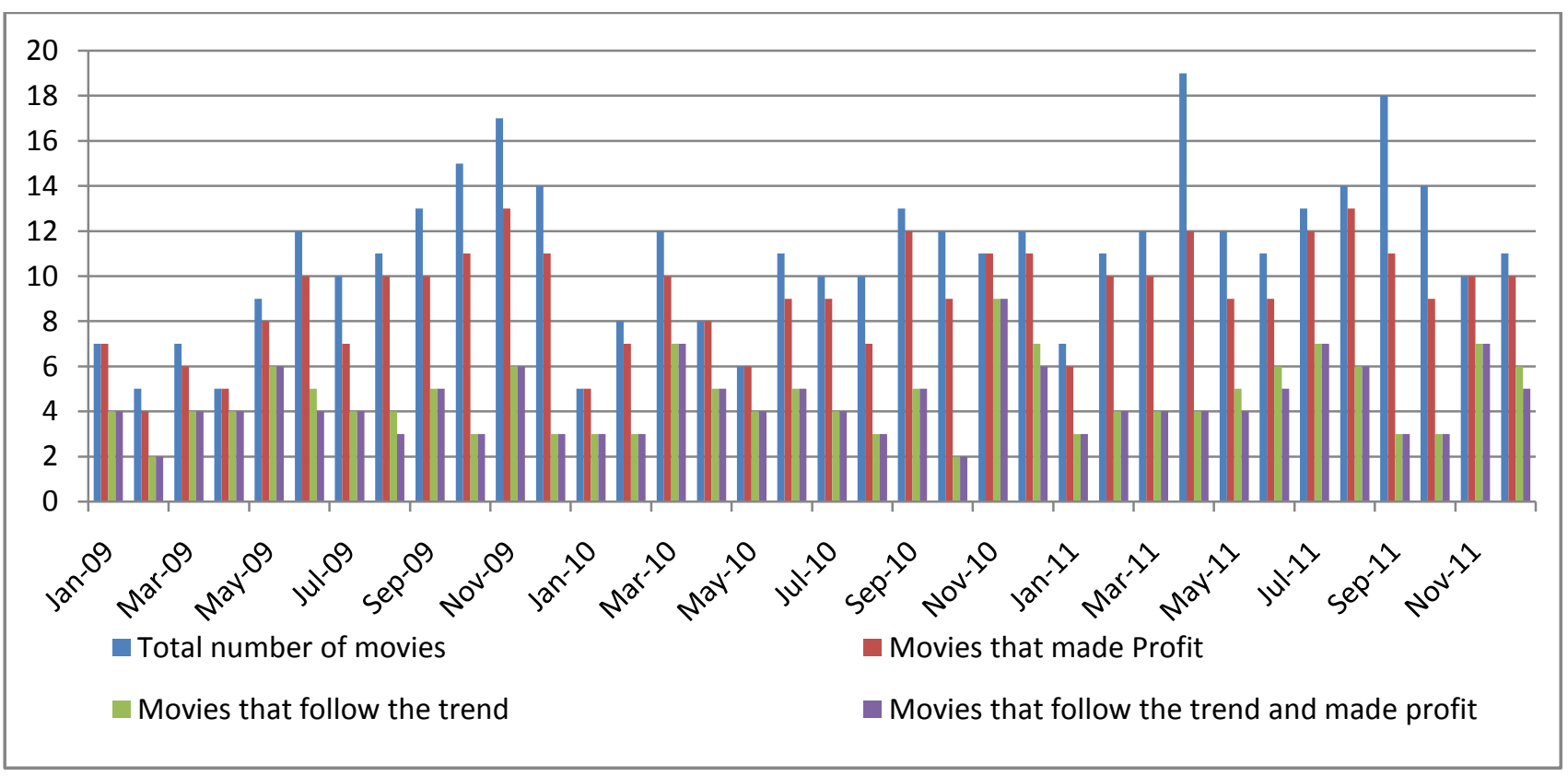

Fig 1: Total number of movies, trend following movies and trend following successful movies

Let us consider a scenario where twenty movies released in a particular month and fifteen out of twenty movies made profit. Among these twenty movies ten movies belong to romance-comedy genres, five movies belong to action genre and remaining five movies belong to thriller genre.Nineout of ten romance-comedy movies made profit. Clearly in this month viewers preferred to watch romantic comedy movies. Alternatively we can say that this month's trend was romance-comedy.

Let's relate this scenario to our chart shown in figure 1. Values of the four parameters we have used in this charts are like following: Total number of movies: 20

Movies that made Profit: 15

Movies that follow the trend: 10

Movies that follow the trend and made profit: 9
We have defined two ratios to validate our findings about the profit making movie business trends. Ratiol is the ratio between Movies that made profit to Total number of movies. Ratio 2 is the ratio between Movies that follow the trend and made profit to Movies that follow the trend. For the above case Ratio1 is .75 and Ratio2 is 0.9 .

We have computed these two ratios from 36 months data, which we have analyzed earlier and plotted the frequency distribution, cumulative percentages in figure 2 and figure 3 respectively. 


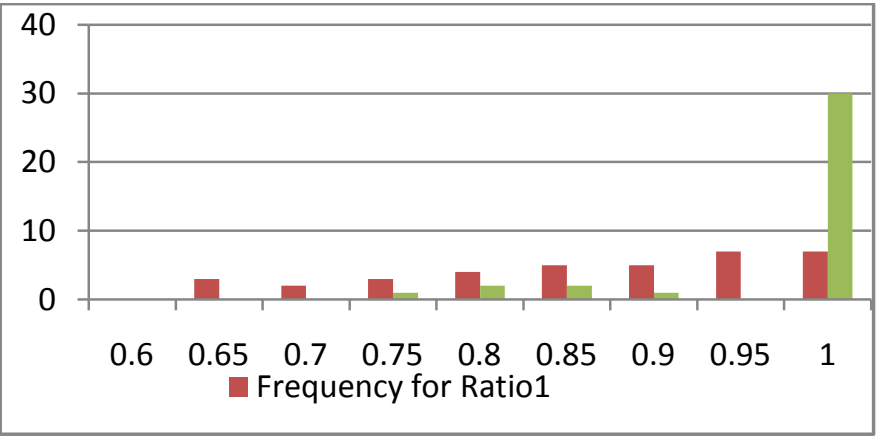

Fig 2: Frequency Distribution

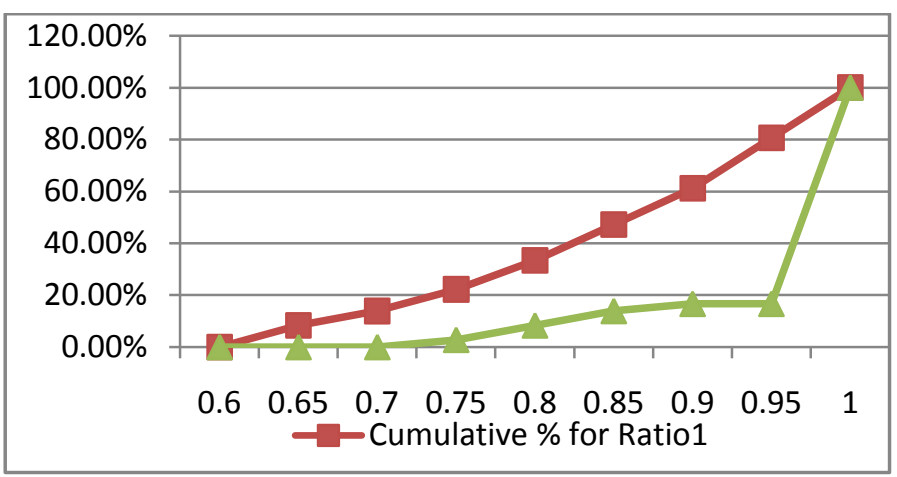

Fig3: Cumulative percentage

As we have mentioned in Section II, we have assumed 5 month as a maximum span or lifetime of the movie business's trend or trends. First three months data has been used to compute three best trends and validated these trends by next two month's trends.

As you can see from the table 3, we have successfully predicted trend/ trends for 19 cases out of 22 cases. This leads us to a success rate of $86.36 \%$.It can be seen from the result of our previous experiment shown in table 1, how frequently business trend changes.

Considering such a volatile nature of movie business trend a success rate of $86.36 \%$ is seems to be a reasonably good result. It is obvious that such a prediction should be very helpful to Distributors, Producers and filmmakers. If a film follows the trend then it will be safe to say that it has a very good chance of being successful.

\section{CONCLUSION AND SCOPE FOR FURTHER WORK}

Note that, it is very difficult even for a human expert to predict the possible profit or loss of a new movie to be released. It seems that the genres of the movie play a significant role in the profit of the movie but it is very difficult to analytically establish the relation of the value of the genres of a given movie with the profit that it makes. But we can certainly try to predict the possible movie trend based on the genres. These trends for future months can be treated as guidelines for the production houses to drive this business towards more profitability. In this paper we have attempted to develop a method using association rule mining to find out the most preferable and popular genres which can be represented as movie business's trend. In our experiment we have achieved a success rate of $86.36 \%$ which is a reasonably good result considering the very high unpredictability of movie business.

Further research work can be conducted in the following areas. We can search for more genres and/or division of an existing genre into subgenres that may led to a higher success rate of prediction. Also we can conduct research for finding features of profitable movie trend in terms of some specific genres possibly using a psychological analysis of peoples' likings or interests in some specific kinds of movies.

\section{REFERENCES}

[1] Information about the films from Wikipedia, http://en.wikipedia.org/wiki/Film [Accessed 9 January 2013]

[2] Information about the film industry from Wikipedia, http://en.wikipedia.org/wiki/Film_industry [Accessed 9 January 2013]

[3] Nash Information Services, The numbers, "Box office data, movie stars, idle speculation", http://www.thenumbers.com/glossary.php [Accessed 25 January 2013]

[4] Information about most expensive films from Wikipedia, http://en.wikipedia.org/wiki/List_of_most_expensive_films [Accessed 9 January 2013]

[5] Information about highest grossing films from Wikipedia, http://en.wikipedia.org/wiki/List_of_highest-grossing_films [Accessed 9 January 2013]

[6] Information about the film "City Island" http://en.wikipedia.org/wiki/City_Island_\%28film\%29 [Accessed 10 January 2013]

[7] Information about the film "Zyzzyx Road" http://en.wikipedia.org/wiki/Zyzzyx_Road [Accessed 10 January 2013]

[8] "Association Rule Mining: Applications in Various Areas" by AkashRajak and Mahendra Kumar Gupta, Proceedings of International Conference on Data Management (ISBN: 023063469-9, Macmillan India Ltd., New Delhi), Ghaziabad, India, pp. 3-7, February 25-26, 2008.

[9] "The Application of Association Rules in Retail Marketing Mix " by Hongwei Liu, Bin Su and Bixi Zhang Proceedings of IEEE International Conference on Automation and Logistics, 2007, page No. 2514 - 2517.

[10] G. Serban, I. G. Czibula, and A. Campan, "A Programming Interface For Medical diagnosis Prediction", StudiaUniversitatis, "Babes-Bolyai", Informatica, LI(1), pages 21-30, 2006.

[11] N. Gupta, N. Mangal, K. Tiwari and P. Mitra, "Mining Quantitative Association Rules in Protein Sequences", In Proceedings of Australasian Conference on Knowledge Discovery and Data Mining - AUSDM, 2006

[12] "Searching customer patterns of mobile service using clustering and quantitative association rule" by So Young Sohn and Yoonseong Kim published in Expert Systems with Applications Volume 34 (2008), Page No. 1070-1077

[13] "Association rules applied to credit card fraud detection" by D. Sa'nchez, M.A. Vila, L. Cerda and J.M. Serrano. Published in Expert Systems with Applications Volume 36 (2009), Page No. 3630-3640

[14] "Mining spatial association rules in census data" by D. Malerba, F. Esposito and F.A. Lisi, In Proceedings of Joint Conf. on "New Techniques and Technologies for Statistcs and Exchange of Technology and Know-how", 2001.

[15] Information about the film genre from Wikipedia, http://en.wikipedia.org/wiki/Film_genre [Accessed 10 January 2013]

[16] Information about the film "Avtar" from IMDB http://www.imdb.com/title/tt0499549/ [Accessed 9 January 2013]

[17] Definitions of Association rule from Wikipedia http://en.wikipedia.org/wiki/Association_rule_learning

[Accessed 12 January 2013] 
[18] Piatetsky-Shapiro, Gregory (1991), Discovery, analysis, and presentation of strong rules, in Piatetsky-Shapiro, Gregory; and Frawley, William J.; eds.,Knowledge Discovery in Databases, AAAI/MIT Press, Cambridge, MA.

[19] Agrawal, R.; Imieliński, T.; Swami, A. (1993). "Mining association rules between sets of items in large databases". Proceedings of the 1993 ACM SIGMOD international conference on Management of data - SIGMOD '93. pp. 207.

[20] IstiSurjandaridanAnnury Citra Seruni, Design of product placement layout in retail shop using market basket analysis, MAKARA, TEKNOLOGI, VOL. 9, NO. 2, NOvEMBER 2005, pp 43-47

[21] BamshadMobasher, Honghua Dai, Tao Luo and Miki Nakagawa , " Personalization based on association rule discovery from web usage data ", WIDM '01 Proceedings of the 3rd international workshop on Web information and data management, pp 9-15

[22] Raymond Kosala, HendrikBlockeel, " Web mining research: a survey ", ACM SIGKDD Explorations Newsletter, Volume 2 Issue 1, June, 2000, pp 1-15

[23] JaideepSrivastava, Robert Cooley, MukundDeshpande and Pang-Ning Tan, "Web usage mining: discovery and applications of usage patterns from Web data", ACM SIGKDD Explorations Newsletter,Volume 1 Issue 2, January 2000, pp 12-23.

of the 9th IFAC Symposium on automated systems based on human skill and knowledge, France: Nancy. 2006.

[31] Creighton, Chad, and Samir Hanash. "Mining gene expression databases for association rules." Bioinformatics 19, no. 1 (2003): 79-86.

[32] Georgii, Elisabeth, Lothar Richter, Ulrich Rückert, and Stefan Kramer. "Analyzing microarray data using quantitative association rules." Bioinformatics 21, no. suppl 2 (2005): ii123ii129.

[33] Carmona-Saez, Pedro, Monica Chagoyen, Andres Rodriguez, OswaldoTrelles, Jose Carazo, and Alberto Pascual-Montano. "Integrated analysis of gene expression by association rules discovery." BMC bioinformatics 7, no. 1 (2006): 54.

[34] Ordonez, Carlos, Norberto Ezquerra, and Cesar A. Santana. "Constraining and summarizing association rules in medical data." Knowledge and Information Systems 9, no. 3 (2006): 1-2.
[24] R Cooley, "Web mining: information and pattern discovery on the World Wide Web ", Proceedings of Ninth IEEE International Conference on Tools with Artificial Intelligence, 1997. pp 558-567.

[25] Lee, Wenke, and Salvatore J. Stolfo. Data mining approaches for intrusion detection. Defense Technical Information Center, 2000.

[26] Lee, Wenke, Salvatore J. Stolfo, and Kui W. Mok. "Mining audit data to build intrusion detection models." In Proceedings of the 4th International Conference on Knowledge Discovery and Data Mining, pp. 66-72. 1998.

[27] Tajbakhsh, Arman, Mohammad Rahmati, and AbdolrezaMirzaei. "Intrusion detection using fuzzy association rules." Applied Soft Computing 9, no. 2 (2009): 462-469.

[28] Lee, Wenke, Salvatore J. Stolfo, and Kui W. Mok. "Adaptive intrusion detection: A data mining approach." Artificial Intelligence Review 14, no. 6 (2000): 533-567.

[29] Ertoz, Levent, Eric Eilertson, AleksandarLazarevic, Pang-Ning Tan, Vipin Kumar, JaideepSrivastava, and Paul Dokas. "Mindsminnesota intrusion detection system." Next Generation Data Mining (2004): 199-218.

[30] Raddatz, M., M. Schlüter, S. C. Brandt, M. Jarke, T. Grimbach, and M. Weck. "Identification and reuse of experience knowledge in continuous production processes." In Proceedings

[35] Ordonez, Carlos, Norberto Ezquerra, and Cesar A. Santana. "Constraining and summarizing association rules in medical data." Knowledge and Information Systems 9, no. 3 (2006): 1-2.

[36] RakeshAgrawal and RamakrishnanSrikant, "Fast algorithms for mining association rules in large databases". Proceedings of the 20th International Conference on Very Large Data Bases, $V L D B$, pages 487-499, Santiago, Chile, September 1994.

[37] Association rules in Data Mining http://searchbusinessanalytics.techtarget.com/definition/associati on-rules-in-data-mining [Accessed on 25 January 2013]

[38] Han, Jiawei, and Micheline Kamber. "Data mining: concepts and techniques (the Morgan Kaufmann Series in data management systems)." Second edition, pp- 230-240.

[39] Han, Jiawei, and Micheline Kamber. "Data mining: concepts and techniques (the Morgan Kaufmann Series in data management systems)." Second edition, pp- 235 
Table 3. Predicted Movie business trend

\begin{tabular}{|c|c|c|c|c|c|c|c|}
\hline \multirow{2}{*}{$\begin{array}{l}\text { Training } \\
\text { Data Set }\end{array}$} & \multicolumn{2}{|l|}{ Best 3 Trends } & \multirow[t]{2}{*}{ No. } & \multirow{2}{*}{$\begin{array}{l}\text { Test } \\
\text { Month }\end{array}$} & \multicolumn{2}{|c|}{ Best Trend of the Test Month } & \multirow[t]{2}{*}{ Result } \\
\hline & Antecedent & Support (\%) & & & Antecedent & Support (\%) & \\
\hline \multirow[t]{4}{*}{ Jan - Mar 09} & Comedy $=\mathrm{Y}$ & 35.71 & \multirow[t]{2}{*}{1} & \multirow[t]{2}{*}{ Apr 09} & \multirow[t]{2}{*}{ Drama $=\mathrm{Y}$} & \multirow[t]{2}{*}{80.00} & \multirow[t]{2}{*}{ Success } \\
\hline & \multirow[t]{2}{*}{ Drama $=\mathrm{Y}$} & \multirow[t]{2}{*}{21.43} & & & & & \\
\hline & & & \multirow[t]{2}{*}{2} & \multirow[t]{2}{*}{ May 09} & \multirow[t]{2}{*}{ Action $=\mathrm{Y}$} & \multirow[t]{2}{*}{66.67} & \multirow[t]{2}{*}{ Success } \\
\hline & Action $=\mathrm{Y}$ & 21.43 & & & & & \\
\hline \multirow[t]{4}{*}{ Apr - Jun 09} & Action $=\mathrm{Y}$ & 50.00 & \multirow[t]{2}{*}{3} & \multirow[t]{2}{*}{ Jul 09} & \multirow[t]{2}{*}{ Adventure $=\mathrm{Y}$} & \multirow[t]{2}{*}{40.00} & \multirow[t]{2}{*}{ Success } \\
\hline & \multirow[t]{2}{*}{ Drama $=\mathrm{Y}$} & \multirow[t]{2}{*}{35.00} & & & & & \\
\hline & & & \multirow[t]{2}{*}{4} & \multirow[t]{2}{*}{ Aug 09} & \multirow[t]{2}{*}{$\begin{array}{l}\text { Thriller }=\text { Y } / \text { Drama }= \\
\text { Y }\end{array}$} & \multirow[t]{2}{*}{27.27} & \multirow[t]{2}{*}{ Success } \\
\hline & Adventure $=\mathrm{Y}$ & 35.00 & & & & & \\
\hline \multirow[t]{4}{*}{ Jul-Sep 09} & Comedy $=\mathrm{Y}$ & 28.00 & \multirow[t]{2}{*}{5} & \multirow[t]{2}{*}{ Oct 09} & Thriller $=\mathrm{Y}$ & 20.00 & Success \\
\hline & Thriller $=\mathrm{Y}$ & 28.00 & & & & & \\
\hline & & & 6 & Nov 09 & Comedy $=$ Y & 35.29 & Success \\
\hline & Drama $=\mathrm{Y}$ & 28.00 & & & & & \\
\hline Oct - Dec 09 & Drama $=\mathrm{Y}$ & 42.86 & 7 & Jan 10 & Action $=\mathrm{Y}$ & 50.00 & Failure \\
\hline & Comedy $=\mathrm{Y}$ & 32.14 & & & & & \\
\hline & & & 8 & Feb 10 & Action $=\mathrm{Y}$ & 37.50 & Failure \\
\hline & Adventure $=\mathrm{Y}$ & 25.00 & & & & & \\
\hline Jan - Mar 10 & Comedy $=\mathrm{Y}$ & 45.00 & 9 & Apr 10 & Comedy $=\mathrm{Y}$ & 55.56 & Success \\
\hline & Action $=\mathrm{Y}$ & 30.00 & & & & & \\
\hline
\end{tabular}




\begin{tabular}{|c|c|c|c|c|c|c|c|}
\hline \multicolumn{8}{|c|}{ Volume 74-No.9, Jul } \\
\hline & & & \multirow[t]{2}{*}{10} & \multirow[t]{2}{*}{ May 10} & \multirow[t]{2}{*}{ Action $=\mathrm{Y}$} & \multirow[t]{2}{*}{57.14} & \multirow[t]{2}{*}{ Success } \\
\hline & Romance $=\mathrm{Y}$ & 30.00 & & & & & \\
\hline \multirow[t]{4}{*}{ Apr - Jun 10} & Comedy $=\mathrm{Y}$ & 45.00 & \multirow[t]{2}{*}{11} & \multirow[t]{2}{*}{ Jul 10} & \multirow{2}{*}{$\begin{array}{l}\text { Action }=\mathrm{y} / \text { Adventure } \\
=\mathrm{Y}\end{array}$} & \multirow[t]{2}{*}{40.00} & \multirow[t]{2}{*}{ Success } \\
\hline & Action $=\mathrm{Y}$ & 40.00 & & & & & \\
\hline & & & \multirow[t]{2}{*}{12} & \multirow[t]{2}{*}{ Aug 10} & \multirow[t]{2}{*}{ Crime $=\mathrm{Y}$} & \multirow[t]{2}{*}{30.00} & \multirow[t]{2}{*}{ Failure } \\
\hline & Adventure $=\mathrm{Y}$ & 40.00 & & & & & \\
\hline \multirow[t]{4}{*}{ Jul-Sep 10} & Comedy $=\mathrm{Y}$ & 34.62 & \multirow[t]{2}{*}{13} & \multirow[t]{2}{*}{ Oct 10} & \multirow[t]{2}{*}{ Action $=\mathrm{Y}$} & \multirow[t]{2}{*}{16.67} & \multirow[t]{2}{*}{ Success } \\
\hline & Drama $=Y$ & 30.77 & & & & & \\
\hline & & & \multirow[t]{2}{*}{14} & \multirow[t]{2}{*}{ Nov 10} & \multirow[t]{2}{*}{ Drama $=Y$} & \multirow[t]{2}{*}{75.00} & \multirow[t]{2}{*}{ Success } \\
\hline & Action $=\mathrm{Y}$ & 30.77 & & & & & \\
\hline \multirow[t]{4}{*}{ Oct - Dec 10} & Drama $=\mathrm{Y}$ & 57.14 & \multirow[t]{2}{*}{15} & \multirow[t]{2}{*}{ Jan 11} & \multirow[t]{2}{*}{ Comedy $=\mathrm{Y}$} & 42.86 & Success \\
\hline & Comedy $=\mathrm{Y}$ & 39.29 & & & & & \\
\hline & & & 16 & Feb 11 & Drama $=\mathrm{Y}$ & 36.36 & Success \\
\hline & Adventure $=\mathrm{Y}$ & 25.00 & & & & & \\
\hline Jan - Mar 11 & Comedy $=\mathrm{Y}$ & 39.13 & 17 & Apr 11 & Thriller $=\mathrm{Y}$ & 21.05 & Success \\
\hline & Thriller $=\mathrm{Y}$ & 30.44 & & & & & \\
\hline & & & 18 & May 11 & Comedy $=\mathrm{Y}$ & 41.67 & Success \\
\hline & Drama $=\mathrm{Y}$ & 26.09 & & & & & \\
\hline Apr - Jun 11 & Comedy $=\mathrm{Y}$ & 44.44 & 19 & Jul 11 & Comedy $=\mathrm{Y}$ & 53.85 & Success \\
\hline & Action $=\mathrm{Y}$ & 29.63 & & & & & \\
\hline & & & 20 & Aug 11 & Drama $=\mathrm{Y}$ & 42.86 & Success \\
\hline & Drama $=Y$ & 22.22 & & & & & \\
\hline Jul - Sep 11 & Comedy $=\mathrm{Y}$ & 36.67 & 21 & Oct 11 & Action $=\mathrm{Y}$ & 21.43 & Success \\
\hline & Romance $=\mathrm{Y}$ & 23.33 & & & & & \\
\hline & & & 22 & Nov 11 & Comedy $=\mathrm{Y}$ & 70.00 & Success \\
\hline & Action $=\mathrm{Y}$ & 16.67 & & & & & \\
\hline
\end{tabular}

